\title{
Effect of DDAVP on nocturnal enuresis in a patient with nephrogenic diabetes insipidus
}

\author{
Susanne Jonat, René Santer, Reinhard Schneppenheim, Tobias Obser, Paul Eggert
}

\begin{abstract}
The case of an 8 year old boy with both nocturnal enuresis and nephrogenic diabetes insipidus is presented. Diagnosis of nephrogenic diabetes insipidus was based on a typical medical history, the characteristic result of a fluid restriction test, the lack of an effect of 1-desamino-8D-arginine (DDAVP) on both urine osmolality and plasma coagulation factors and, finally, the detection of a hemizygous missense mutation within the arginine vasopressin (AVP) receptor gene. Hydrochlorothiazide treatment and dietary measures reduced the patient's urine volume to one third of its original volume. However, this had no effect on enuresis. The daily intranasal application of DDAVP did not further reduce urine output but dramatically decreased the frequency of bed wetting. This observation contradicts the common notion that the therapeutic effect of DDAVP in nocturnal enuresis is the result of compensation for a nocturnal AVP deficit. Rather, it points to a different mode of action of DDAVP in patients with enuresis. It is hypothesised that central AVP receptors are a target of DDAVP and that they might play an important role in the pathogenesis of nocturnal enuresis.

(Arch Dis Child 1999;81:57-59)
\end{abstract}

Keywords: nocturnal enuresis; nephrogenic diabetes insipidus; 1-desamino-8-D-arginine effect

Treatment of primary nocturnal enuresis with 1-desamino-8-D-arginine (DDAVP) is based on the hypothesis that antidiuretic hormone secretion is insufficient during the night. ${ }^{1-2}$ It is assumed that nocturnal deficiency of arginine vasopressin (AVP) causes an increased urine volume, and that this increased urine volume exceeds bladder capacity and results in bed wetting. ${ }^{2}$ Although the therapeutic effect of DDAVP is undisputed, ${ }^{3}$ controversy still exists regarding the hypothesis of nocturnal AVP deficiency. ${ }^{4}$ With the following case report of an 8 year old boy with both nephrogenic diabetes insipidus and primary nocturnal enuresis we would like to contribute to the discussion about the mechanism of action of DDAVP and the pathophysiology of nocturnal enuresis.

\section{Case report}

An 8 year old boy presented with a fluid intake of 4-6 litres/day and comparably high urinary volumes. His medical history is remarkable in that several examinations for failure to thrive and muscle weakness were performed between the age of 2 and 5 years. In addition, he showed typical symptoms of nocturnal enuresis such as bed wetting for more than four nights a week and the characteristic very deep sleep. Neither a 13 year old brother nor other family members had similar symptoms.

The patient's height of $116 \mathrm{~cm}$ and his weight of $19.8 \mathrm{~kg}$ were below the third centile. With the exception of a systolic murmur caused by a very small ventricular septal defect, the clinical examination was unremarkable.

From the medical history, diabetes insipidus was suspected and a fluid restriction test was performed. After nine hours, urine osmolality had only increased from 103 to $193 \mathrm{mmol} / \mathrm{kg}$, and serum osmolality increased from 300 to $323 \mathrm{mmol} / \mathrm{kg}$. The finding of a significantly increased AVP plasma concentration of 25.8 $\mathrm{pg} / \mathrm{ml}$ at the end of the test, together with the fact that a test dose of DDAVP had no effect on urine osmolality, suggested nephrogenic diabetes insipidus. This diagnosis was confirmed by the lack of an effect of intravenously applied DDAVP on plasma concentrations of factor VIII and von Willebrand factor (fig 1). In particular, supranormal von Willebrand factor multimers were not seen in the patient's plasma. A defect of the tubular AVP receptor, designated AVPR2, was therefore considered to be the underlying cause of nephrogenic diabetes insipidus in our patient. ${ }^{6}$ This was confirmed by sequencing the AVPR2 gene on chromosome Xq28. A hemizygous missense mutation $(\mathrm{G} \rightarrow \mathrm{A})$ in position 410 of the AVPR2 cDNA was detected, resulting in an amino acid substitution (R137H) (fig 2).

After treatment with hydrochlorothiazide $(1 \mathrm{mg} / \mathrm{kg} /$ day $)$ and a salt restricted, low protein diet, ${ }^{7}$ the symptoms improved. Fluid intake and urinary volume decreased to 1.5-2 litres/ day. However, this treatment had no effect on

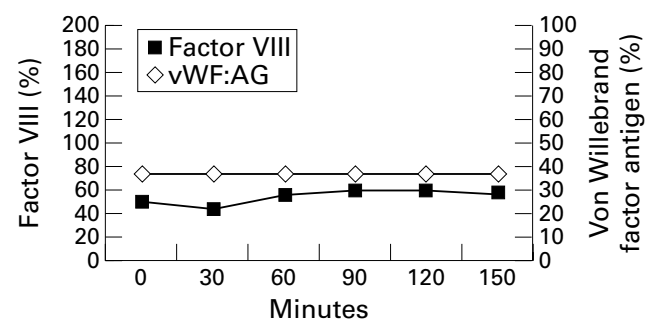

Figure 1 Factor VIII and von Willebrand factor responses to DDAVP infusion. According to the method of Bichet and colleagues ${ }^{7}$ blood samples were drawn every 30 minutes and centrifuged immediately. The patient received a 20 minute infusion of $0.3 \mu \mathrm{g}$ of DDAVP/kg body weight between minutes 30 and 50. The plasma was separated and analysed for factor VIII and von Willebrand factor by coagulation assay and enzyme linked immunosorbent assay, respectively. 


\section{AVPR2 exon 2}

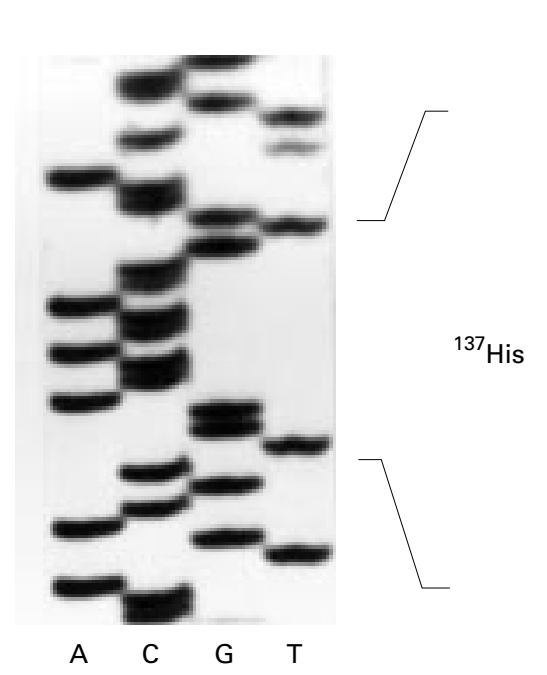

mut

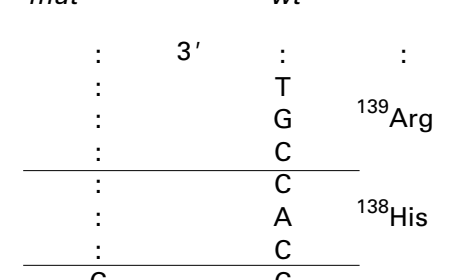

Figure 2 DNA sequence of exon 2 of the patient's AVPR2 gene. The region of codon 137 exhibiting the hemizygous missense mutation $G 410 A$ is shown, resulting in the amino acid substitution R137H. cell membrane, and although these few receptors were able to stimulate the second messenger system, all patients carrying the $\mathrm{R} 137 \mathrm{H}$ mutation had the typical signs of nephrogenic diabetes insipidus. That receptor function was indeed severely impaired was also demonstrated in our patient, in whom pharmacological doses of DDAVP did not result in any functional response, neither in tubular water absorption nor in endothelial release of coagulation factors.

Nevertheless, our patient showed a dramatic response to DDAVP with regard to bed wetting. Apart from renal and extrarenal AVPR2 receptors, two other types of AVP binding receptors with sequence homology to AVPR2, but a different chromosomal localisation of the corresponding genes, have been described. The first is the liver-type receptor, designated AVPR1, which mediates the vascular or pressor activity of AVP. By means of northern blotting, this receptor was also found in very small amounts in mesangial cells of the kidney. However, DDAVP is not considered to be a ligand for AVPR1 and this, together with the observation that blood pressure was not changed and fluid intake and urinary output were not increased in our patient by the administration of DDAVP, make it unlikely that AVPR1 receptors play a role in the aetiology of disease in our patient. Another AVP binding receptor, AVPR3, is found in the brain and was originally cloned from a pituitary cDNA library. ${ }^{11}{ }^{12}$ Based upon the observation

\begin{abstract}
that these adenohypophyseal receptors, unlike the AVPR2 receptor, did not appear to be coupled to adenylate cyclase but rather to the phospholipase C pathway, they were also designated AVPR1b receptors as opposed to the AVPR1a receptors previously characterised on liver and blood vessels. ${ }^{13}$ Although DDAVP was originally considered to be an AVPR2 receptor selective agonist, it has recently been shown that it is a full agonist of AVPR1b receptors, with an even stronger inhibition of AVP binding to AVPR1b than to AVPR2 receptors. ${ }^{14}$ Therefore, from our observations, we speculate that AVPR1b receptors are a target of DDAVP in children with enuresis and that they possibly play a role in the central nervous regulation of bladder control. Indeed, it has been shown that AVPR $1 b$ expression in the brain is not confined to the anterior pituitary and that AVP also binds to several structures of the limbic system, to hypothalamic nuclei, and to the area of the nucleus of the solitary tract. ${ }^{15}$ Because no conclusive theory for the underlying cause of nocturnal enuresis has been formulated to date, one might speculate further that central AVPR1b receptors play an important role in its pathogenesis. The observations that nocturnal enuresis in children is characteristically combined with a very deep sleep and that nocturnal bladder control generally matures with age is more compatible with an impairment of different brain functions regulated through AVPR1b receptors than with the current theory of inappropriate nocturnal AVP secretion, which provides no explanation for these phenomena. recently been elucidated. ${ }^{9}$ The mutant receptor protein has been shown to be retained almost completely in the interior of the cell. Although very few mutant receptors were found on the

Discussion enuresis is based on the hypothesis that AVP increased urine volume, which exceeds bladder capacity. ${ }^{2}$ Although convincing at first glance, that patients with enuresis have a defect at the AV receptor level. ${ }^{5}$ Our present case provi quen compensation for this deficiency. The idhe diagnosis of nephrogenic diabetes idus was complete in our patient, including the several previous cases, ${ }^{8-10}$ and the mechanism resulting in impaired receptor function has
\end{abstract}


In summary, this unusual case points to a novel mode of action of DDAVP in children with enuresis and we suggest that central nervous AVP binding receptors play a role in the pathogenesis of nocturnal enuresis.

1 Rittig S, Knudsen UB, Nørgaard JP, Pedersen EB, Djurhuus JC. Abnormal diurnal rhythm of plasma vasopressin and urinary output in patients with enuresis. Am $\mathcal{F}$ Physiol 1998;21:442-7.

2 Carpenter RO. Disorders of elimination. In: Oski FA, ed. Principles and practice of pediatrics. Philadelphia: Lippincott, 1994:748-50.

3 Moffatt MEK, Harlos S, Kirshen AJ, Burd L. AVP acetate and nocturnal enuresis: how much do we know? Pediatrics 1993;92:420-5.

4 Fefferman RA. Desmopressin approval question [letter]. Pediatrics 1994;93:1022-3.

5 Eggert P, Kühn B. Antidiuretic hormone regulation in patients with primary nocturnal enuresis. Arch Dis Child 1995;73:508-11.

6 Bichet DG, Razi M, Lonergan M, et al. Hemodynamic and coagulation responses to 1-desamino (8-d-arginine) vasopressin in patients with congenital nephrogenic diabetes insipidus. N Engl f Med 1988;318:881-7.

7 Bergstein JM. Nephrogenic diabetes insipidus. In: Behrmann RE, Kliegman RE, Arvin AM, eds. Textbook of pediatrics. Philadelphia: WB Saunders, 1996:1510-11.
8 Bichet DG, Arthus MF, Lonergan M, et al. X-linked nephrogenic diabetes insipidus mutations in North America an the Hopewell hypothesis. F Clin Invest 1993;92:1262-8.

9 Schöneberg T, Schulz A, Biebermann H, et al. V2 vasopressin receptor dysfunction in nephrogenic diabetes insipidus caused by different molecular mechanisms. Hum Mutat 1998;12:196-205.

10 Shoji Y, Takahashi T, Suzuki Y, et al. Mutational analyses of AVPR2 gene in three Japanese families with $\mathrm{X}$-linked nephrogenic diabetes insipidus: two recurrent mutations, $\mathrm{R} 137 \mathrm{H}$ and deltaV278, caused by the hypermutability at CpG dinucleotides. Hum Mutat 1998;12(suppl 1):278-83.

11 deKeyzer Y, Auzan C, Lenne F, et al. Cloning and characterization of the human V3 pituitary vasopressin receptor. FEBS Lett 1994;356:215-20.

12 Sugimoto T, Saito M, Mochizuki S, Watanabe Y, Hashimoto $\mathrm{S}$, Kawashima $\mathrm{H}$. Molecular cloning and functional expression of a cDNA encoding the human V1b vasopressin receptor. F Biol Chem 1994;269:27088-92.

13 Jard S, Gaillard RC, Guillon G, et al. Vasopressin antagonists allow demonstration of a novel type of vasopressin receptor in the rat adenohypophysis. Mol Pharmacol 1986;30:171-7.

14 Saito M, Tahara A, Sugimoto T. 1-desamino-8-D-arginine vasopressin (DDAVP) as an agonist on V1b vasopressin receptor. Biochem Pharmacol 1997;53:1711-17.

15 Lolait SJ, O'Carroll AM, Mahan LC, et al. Extrapituitary expression of the rat V1b vasopressin receptor gene. Proc Natl Acad Sci USA 1995;92:6783-7. 